\title{
Development and Precise Positioning Control of a Novel Linear Motor
}

\author{
Xinxin Shi ${ }^{1, *}$ and Jiacai Huang ${ }^{1}$ \\ ${ }^{1}$ School Of Automation, Nanjing Institute Of Technology, No. 1 Hongjing Road, \\ Nanjing 211167, P.R. China \\ *Corresponding Author: Sxx@Njit.Edu.Cn
}

\begin{abstract}
A Novel Two-Phase Brushless Tubular Linear Motor And Its Precise Positioning Control System Are Presented In This Paper. The Magnetic Field Distribution In The Air Gap Of The Linear Motor Is Trapezoidal With Optimization By Halbach Magnet Array, And An Ironless Structure Is Adopted To Eliminate Force Ripples. A Simple And Practical Controller Called Active Disturbance Rejection Controller Is Used To Implement Positioning Control Of The Linear Motor Prototype, Which Is Affected By Parameter Uncertainties And Friction. Simulation And Experimental Results Show That The Position Step Response Is Smooth And Micrometer Positioning Accuracy Is Achieved Without Significant Overshoot Or Oscillation. It Can Be Concluded That The Proposed Linear Motor Is Suitable For Smooth And Precise Linear Motion Applications.
\end{abstract}

Keywords: Linear Motor; Positioning Control; Active Disturbance Rejection Controller; Smooth Motion.

\section{Introduction}

The Objective Of The Work Described In This Paper Is To Present A Novel Linear Motor Capable Of Smooth Linear Motion And Precise Positioning With The Help Of An Active Disturbance Rejection Controller (ADRC). In Automation, Robotics And Other Industry Applications, The Need For An Intelligent Linear Motion Is Getting Higher, Such As High Speed, High Precision, And Smooth Motion [1-3]. Traditionally, Rotary Motors And Auxiliary Mechanisms Such As Gears And Ballscrews Are Used To Obtain Linear Motion, Which Brings Complications Including Additional Inertia, Friction And Backlash. Compared With Their Rotary Counterparts, Linear Motors Are More Suitable For High-Speed, HighPrecision And Smooth Linear Motion Applications.

Up To Now, Various Structures Of Linear Motors Have Been Proposed [4-7]. However, The Ripple Force Exists In Almost All Variations Of Linear Motors, As Long As A Ferromagnetic Core Is Used For The Windings. Since The Ripple Force Is Mainly Resulting From The Slotting And The Finite Length Of The Iron-Core Translator, It Is A Practical Approach To Adopt An Ironless Design In The Core Of The Windings [8].

Although An Ironless Design In The Core Of The Windings Can Reduce The Ripple Force Significantly, It Will Reduce The Maximum Force And The Efficiency Of The Linear Motor Simultaneously Since There Is No Iron Yoke To Concentrate The Magnetic Field [9]. Ozgur Ustun Adopted A Method To Improve The Force Of The Ironless Linear Motor By Increasing The Number Of Winding Turns [10]. It Is A Good Way For His Specific Printed-Circuit Winding. However, It Is Not Suitable For Other Common Windings. In This Paper, Halbach Magnet Array Is Adopted To 
Enhance Flux Density In The Air Gap Together With High-Energy-Density Neodymium Iron Boron (Ndfeb) Permanent Magnets (Pms) [11].

Similar To The Categories Of Rotary Brushless PM Motors [12-13], Linear Motors Can Be Divided Into Two Types. They Are The Permanent Magnet Synchronous Linear Motor (PMSLM) And The Brushless Direct Current Linear Motor (BDCLM). The Difference Between Them Is That The PMSLM And The BDCLM Have Sinusoidal And Trapezoidal Magnetic Field Distribution In The Air Gap Respectively. Both Of Them Have Their Own Advantages And Disadvantages, And The Choice Of Them Depends On The Specific Applications. Compared With The PMSLM, The BDCLM Has The Advantage Of Simple Operation, Which Acts As The Direct Current (DC) Motor.

Furthermore, Some Uncertainties Such As Parameter Variations, Friction, Uncertain Payloads And External Disturbances Exist In The Direct-Drive Systems. However, The Classical Proportional-Integral-Derivative (PID) Control Law Can Not Handle These Uncertainties Effectively [14]. Therefore, The Motion Controller Should Be Well Designed To Be Robust Against Uncertainties [15].

Up To Now, There Have Been Many Control Strategies For Linear Motion Control System [16-18]. Some Of Them Are Complex In Theory And Difficult To Implement In Practice. Here, A Simple ADRC Is Adopted. The Controller Takes Into Account The Effect Of Model Uncertainties Coming From The Friction And Electrical Parameters. As A Result, The Linear Motor Prototype Achieves Smooth Motion And Precise Positioning Performance Without Any Overshoot Or Oscillation To A Step Position Command.

The Paper Is Organized As Follows. Electromechanical Design And Mathematical Model Of The Proposed Linear Motor Are Presented In Section 2 And Section 3 Respectively. The ADRC And Precise Positioning Control System Are Introduced In Section 4. Experimental Setup And Positioning Control Results Are Shown In Section 5, And Conclusions Are Drawn In Section 6.

\section{Electromechanical Design}

\subsection{Structure of the Linear Motor}

The Developed Linear Motor Is Essentially A Tubular, Moving-Coil, Permanent Magnet, Brushless, Direct Current (DC) Linear Motor. Schematic Structure Of The Linear Motor Is Illustrated In Figure 1. Since The Linear Motor Is Axially Symmetrical, Only A Quarter Of It Is Displayed. $Z$ Denotes The Axis And $R$ Denotes The Radius.

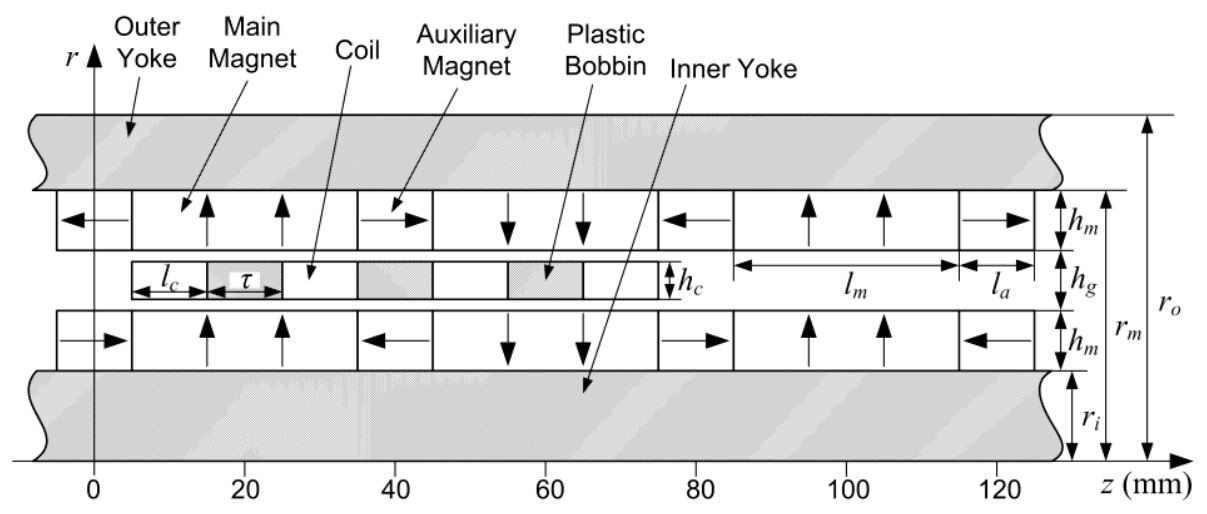

Figure 1. Schematic Structure Of The Linear Motor 
As Shown In Figure 1, The Ndfeb PM Rings Are Mounted On Both Inner Yoke And Outer Yoke Which Constitute The Stator. Yokes Are Made Of Iron As The Pathway Of Magnetic Flux. Coils Are Wrapped Around A Hollow Bobbin Which Is Made Of Engineering Plastics To Constitute The Mover. Besides The Main Radial Magnetized Pms, The Flux Density In The Air Gap Is Enhanced By Adding Auxiliary Axially Magnetized Pms To Form Halbach Array [19]. Theoretically, The Stroke Of This Linear Motor Is Infinite As Long As The Length Of The Halbach Array Is Infinite Too. Herein, A Zone Of 120 Mm Length Is Separated From The Linear Motor For Analysis.

With The Help Of Ansoft Maxwell Software, Magnetic Field Distribution In The Air Gap Can Be Obtained As Shown In Figure 2. Here, Figure 2 Indicates The Magnitude Of The Magnetic Flux Density, And The Direction Of It Is Denoted In Figure 1. From Figure 2, It Can Be Seen That The Magnetic Flux Density Waveform Is Approximately Trapezoidal. Moreover, The Length Of The Constant Magnitude Area Is Almost Equal To That Of The Main Magnet. Therefore, If The Coil Current In This Area Is Also Constant, Smooth Thrust Will Be Produced.

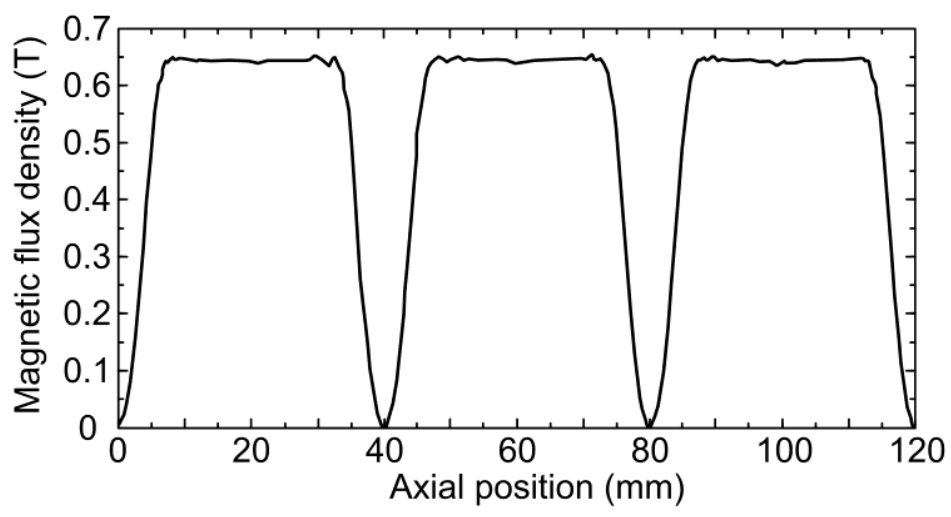

Figure 2. Magnetic Field Distribution of the Linear Motor

The Mover Is Attached To A Joint Which Is Supported By A Low-Friction Linear Guideway. Furthermore, The Ironless Core Eliminates The Ripple Thrust Effect. All Of These Improve The Dynamic Performance Of The Linear Motor. With Great Efforts On Design And Optimization [20, 21], Specific Dimensions Of The Linear Motor Are Established And Finally A Prototype Has Been Manufactured. Dimensions Of The Prototype Are Presented In Table 1.

Table 1. Dimensions of the Prototype

\begin{tabular}{ccc}
\hline Items & $\begin{array}{c}\text { Symb } \\
\text { ols }\end{array}$ & $\begin{array}{c}\text { Values (Units: } \\
\text { Mm) }\end{array}$ \\
\hline Axial Length Of The Main PM & $L_{m}$ & 30 \\
Axial Length Of The Auxiliary & $L_{a}$ & 10 \\
PM & $L_{c}$ & 10 \\
Axial Length Of Each Coil & $T$ & 10 \\
Coil Pitch & $R_{i}$ & 10 \\
Inner Yoke Radius & $H_{m}$ & 6 \\
Radial Width Of The PM & $R_{m}$ & 27 \\
Outer Radius Of The Outer PM & $R_{o}$ & 36 \\
Outer Radius Of The Outer Yoke & &
\end{tabular}




$\begin{array}{ccc}\text { Radial Width Of The Air Gap } & H_{g} & 5 \\ \text { Radial Width Of Each Coil } & H_{c} & 3.7\end{array}$

\subsection{Working Principle of the Linear Motor}

In This Linear Motor, Four Coils Are Linked Alternately In A Serial Way And Therefore Two Phases Are Formed. That Is To Say, Coil A And Coil X Are Linked Serially To Form Phase 1, And Coil B Is Linked With Coil Y Also Serially To Constitute Phase 2. Two Leads Of Each Phase Are Taken Out, So That, It Is Possible To Control The Phase Currents Individually. Winding Directions Of Coils In Each Phase Are Opposite To Counteract The Magnetic Fields Caused By Coil Currents.

Only One Phase Is Powered In Normal Operation. At The Beginning, The Mover Is Located In The Position Indicated In Figure 3(A). When Phase 1 Is Powered And Phase 2 Is Not, Current Begins To Flow In Coil A And Coil X. As Winding Directions Of These Two Coils Are Opposite And They Are Linked Serially, Current Directions Of Them Are Also Opposite, Which Can Be Seen In Figure 3(A). Meanwhile, Directions Of The Magnetic Flux Acting On Coil A And Coil X Are Opposite, Too. According To Fleming's Left Hand Rule, Electromagnetic Forces Acting On Coil A And Coil X Are In The Same Direction. With The Action Of The Generated Thrust, The Mover Starts To Move.

When The Mover Has Arrived At The Position Shown In Figure 3(B), Phase 1 Is Out Of Power. Meanwhile, Phase 2 Is Powered But The Current Is Commutated. Current Directions Of Coil B And Coil Y Are Denoted In Figure 3(B). Just As The Aforementioned Analysis, The Generated Thrust Is In The Same Direction As Before. Therefore, The Mover Can Travel Continuously Along The Original Direction.

Current Switches From One Phase To Another Every 20 Mm In Order To Ensure The Magnetic Flux Density Acting On Current-Carrying Coils Is Approximately Constant. Along The Whole Stroke, The Choices Of Powered Phase And The Phase Current Direction Depend On The Position Of The Mover, Which Is Detected By Optical Linear Encoder.

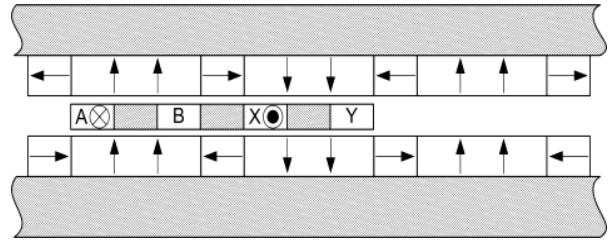

(A)

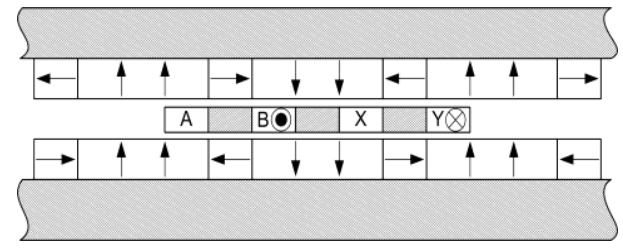

(B)

Figure 3. Working Principle Of The Linear Motor (A) Initial Position (B) Commutation Position

\section{Mathematical Model of the Linear Motor}

The Linear Motor Proposed Herein Can Be Regarded As An Energy Converter, Which Transforms Energy From Electrical Form Into Mechanical Form In A Controllable Way. In The Following, Mathematical Model Of The Linear Motor Indicates The Energy Transforming Process Clearly.

Dynamics Of The Linear Motor Can Be Viewed As Comprising Two Components: Electrical And Mechanical Dynamics. The Components Are Coupled And Affect Each Other. Magnetic Flux Density In The Air Gap Is The Energy 
Medium, Which Acts On The Phase Current And Therefore The Thrust Is Generated.

Phase 1 And Phase 2 Are Controlled Individually. Dynamic Characters Of Each Phase Are Almost The Same, And Only One Phase Is Powered When Linear Motor Travels. Therefore, Only One Phase Is Needed To Be Modeled. Electrical And Mechanical Dynamics Of The Linear Motor Can Be Expressed As Follows:

$$
\left\{\begin{array}{l}
E+R i+L(d i / d t)=u \\
m \ddot{x}+D \dot{x}+F_{r}=F \\
E=K_{e} \dot{x} \\
F=K_{f} i
\end{array}\right.
$$

Where $X$ Denotes The Mover Position; $U, R, L, I$ Denote The Electrical Parameters: Input Voltage, Phase Resistance, Phase Inductance And Phase Current Respectively; $M$ Is The Mass Of The Moving Part Including Load And The Coil Assembly; $D$ Is The Viscous Damping Coefficient Of The System; $F$ Denotes The Generated Electromagnetic Force; $F_{r}$ Is The Lumped Effect Of Uncertain Nonlinearities Such As Friction And External Random Disturbances; $K_{e}$ Is The Back Electromotive Force (EMF) Constant Of The Linear Motor, $K_{f}$ Denotes An Electrical-Mechanical Energy Conversion Constant. Table 2 Gives The Specifications Of The Linear Motor.

It Can Be Concluded From The Mathematical Model That The Coupling Electromagnetic Terms Are The Back EMF Denoted By $E$ And The Generated Force Denoted By $F$. Here, There Is No Need To Know The Exact Model Of Friction And Other Uncertain Disturbances. The Reason Is That The ADRC Adopted Here Has The Ability To Reject Uncertainties And Disturbances Actively, Which Is Presented In The Following Section.

Table 2. Specifications of the Linear Motor

\begin{tabular}{cc}
\hline Items & Values \\
\hline Resistance $(R)$ & $3.4 \Omega$ \\
Inductance $(L)$ & $4.42 \mathrm{Mh}$ \\
Flux Density In The Gap & $0.65 \mathrm{~T}$ \\
Mass Of Moving Part $(M)$ & $250 \mathrm{G}$ \\
Force Constant $\left(K_{f}\right)$ & $18 \mathrm{~N} / \mathrm{A}$ \\
Back EMF Constant $\left(K_{e}\right)$ & $18 \mathrm{Vs} / \mathrm{M}$ \\
Viscous Damping Coefficient & $4 \mathrm{Ns} / \mathrm{M}$ \\
$(D)$ & 84 \\
Turns Of Each Coil & $100 \mathrm{Mm}$ \\
Stroke &
\end{tabular}

\section{Positioning Control of the Linear Motor}

\subsection{ADRC}

In Control Engineering, Motors Are Usually Used For Testing Different Control Strategies. It Is Well Known That There Are Some Uncertainties In Motion Control Systems Such As Unidentified Friction Effect, Uncertain External Disturbances And The Plant Parameter Variations, Particularly When The Current Switches From One Phase To Another In This Kind Of The Linear Motor. All Of These Uncertainties 
Can Be Viewed As Total Disturbance, And It Can Be Observed And Compensated By A Disturbance Observer. Herein, An Active Disturbance Rejection Control (ADRC) Is Used To Handle This Problem.

ADRC Was First Proposed By J. Han, A Professor Of Chinese Academy Of Sciences. ADRC Is A Novel Digital Control Law Which Is Not Predicated On An Accurate Or Detailed Dynamic Model Of The Plant And Is Extremely Tolerant Of Uncertain Disturbances And Easy To Use In Modern Industry Practice [22, 23]. The Whole ADRC Technology Consists Of Four Parts: A Simple Differential Equation To Be Used As A Transient Profile Generator Denoted As Tracking Differentiator (TD), An Extended State Observer (ESO) To Be Used For Estimating The Total Disturbance, Nonlinear Feedback Combination Of State Errors (NLSEF), And Total Disturbance Compensation To Generate The Final Control Action.

The Standard ADRC Is Presented For A Second-Order Plant. Here, A First-Order ADRC Regardless Of TD Is Used For Simplification. Figure 4 Shows The FirstOrder ADRC Topology With A First-Order Single-Input-Single-Output (SISO) Plant As

$$
\left\{\begin{array}{l}
\dot{x}=f(x, w(t), t)+b u \\
y=x
\end{array}\right.
$$

Where, $B$ Is The Coefficient Of The Plant Model, $U$ Is The Input Variable Calculated By ADRC To Manipulate The Plant, And $Y$ Is The Output, Which Is Measured And Controlled To Behave As The Desired Signal $Y^{*} . F(X, W(T), T)$ Can Be Viewed As Total Disturbance.

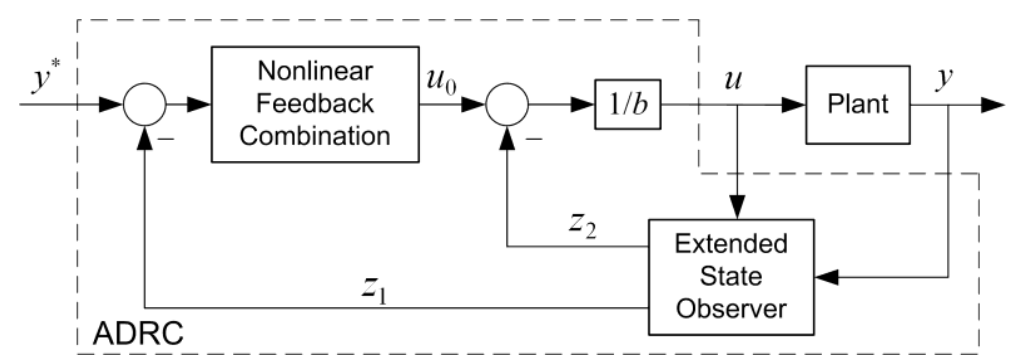

Figure 4. Topology of First-Order ADRC

The Extended State Observer Is Implemented In Discrete Form, With A Sample Period Of $H$ For State Updates, As

$$
\left\{\begin{array}{l}
e=z_{1}-y \\
z_{1}=z_{1}+h \cdot\left(z_{2}-\beta_{1} \cdot e+b \cdot u\right) \\
z_{2}=z_{2}-h \cdot \beta_{2} \cdot \operatorname{fal}(e, \alpha, \delta)
\end{array}\right.
$$

With Nonlinear Feedback Combination, $U_{0}$ Can Be Presented As

$$
\left\{\begin{array}{l}
e_{1}=y^{*}-z_{1} \\
u_{0}=\beta \cdot \operatorname{fal}\left(e_{1}, \alpha, \delta\right)
\end{array}\right.
$$

Finally, The Actual Control Law Is Given As

$$
u=\left(u_{0}-z_{2}\right) / b
$$

Among The Aforementioned Equations, $Y^{*}$ Is The Desired Signal, $Z_{1}$ Is The Estimation Of The Output Value, And $Z_{2}$ Is The Extended State Which Represents 
The Total Disturbance. $B, B_{1}$, And $B_{2}$ Are The Controller Gains. The Nonlinear Function Is Defined As Follows:

$$
f a l(e, \alpha, \delta)= \begin{cases}e \cdot \delta^{\alpha-1}, & |e| \leq \delta \\ |e|^{\alpha} \cdot \operatorname{sign}(e), & |e|>\delta\end{cases}
$$

\subsection{Precise Positioning Control System}

The Purpose Of Constructing Positioning Control System In This Paper Is To Test The Step Response Of The Proposed Linear Motor To A Given Position Order. The Linear Motor Positioning Control System Consists Of Three Serial-Connected Subsystems: $\Sigma_{1}, \Sigma_{2}$, And $\Sigma_{3}$. Furthermore, The Electrical And Mechanical Dynamics Of The Linear Motor Can Be Rewritten As Follows:

$$
\left\{\begin{array}{l}
\sum_{1}: \dot{x}=v \\
\sum_{2}: \dot{v}=-(D / m) \cdot v-F_{r} / m+\left(K_{f} / m\right) \cdot i \\
\sum_{3}: \dot{i}=-(R / L) \cdot i-\left(K_{e} / L\right) \cdot v+(1 / L) \cdot u \\
y=x
\end{array}\right.
$$

Where The Output Of The Third Subsystem I Is The Input To The Second Subsystem $\Sigma_{2}$, And The Output Of The Second Subsystem $V$ Is The Input To The First Subsystem $\Sigma_{1}$. Therefore, Precise Positioning Control System Of The Linear Motor Can Be Constructed With Cascaded First-Order ADRC As Figure 5 Shows.

Similar To The Back-Stepping Technique, We Apply ADRC1 To $\Sigma_{1}$ And ADRC2 To $\Sigma_{2}$ Using $U_{1}=V$ And $U_{2}=I$ As Pseudo Control Variables Respectively. Moreover, Once $U_{1}$ Is Determined, It Is Then Viewed As The Order Signal For $\Sigma_{2}$, Where ADRC2 Is Applied. Similarly, Once $U_{2}$ Is Determined, It Is Then Viewed As The Order Signal For $\Sigma_{3}$, And ADRC3 Is Used To Generate The Actual Control Variable $U$. Here, $\Sigma_{1}$ Is A Pure Single Integral Plant And Therefore ESO Is Eliminated In ADRC1. $-(D / m) v-F_{r} / m$ Plus Uncertain Disturbances Can Be Viewed As The Extended State Of $\Sigma_{2}$, And $-(R / L) i-\left(K_{e} / L\right) v$ Plus External Disturbances Can Be Viewed As The Extended State Of $\Sigma_{3}$.

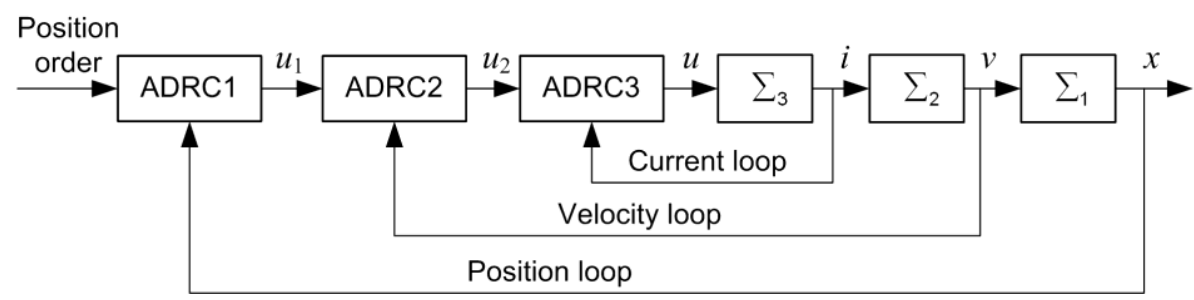

Figure 5. Precise Positioning Control System of the Linear Motor

\section{Experiments}

\subsection{Experimental Setup}

Experimental Setup Of The Linear Motor Positioning Control System Is Given In Figure 6. ADRC Is Implemented On A Digital-Signal-Processing (DSP) Controller 
Board With Chip TMS320F2812. The DSP Emulator Is Used For Program Debugging And Downloading. The Linear Motor Is Unloaded And The Position Order Is Given In The Program. To Measure The Position Of The Moving Part, An Optical Linear Encoder With A Resolution Of $5 \mathrm{Mm}$ Is Attached On The Base Of The Stator. Velocity Signal Is Obtained By The Differential Of Position Signal. Current Sensors Based On Hall-Effect Are Used To Detect The Currents Flowing In Phase 1 And Phase 2 Respectively.

Position And Current Information Are Supplied To The DSP Card Through Input/Output Interfaces And Extended 16-Bit Analog-To-Digital (A/D) Channels. 24V DC Power Supply Is Used In This Experiment. Each Phase Is Connected Across An H-Bridge Circuit, Which Is Composed Of Four Metallic Oxide Semiconductor Field Effect Transistors (MOSFET). Pulse-Width-Modulation (PWM) Waveforms, The Outputs Of The Controller, Are Applied To Gates Of Each MOSFET With The Help Of Gate Drivers. Experimental Data Are Transmitted To The Personal Computer (PC) Through An Ethernet Cable For Analysis And Display.

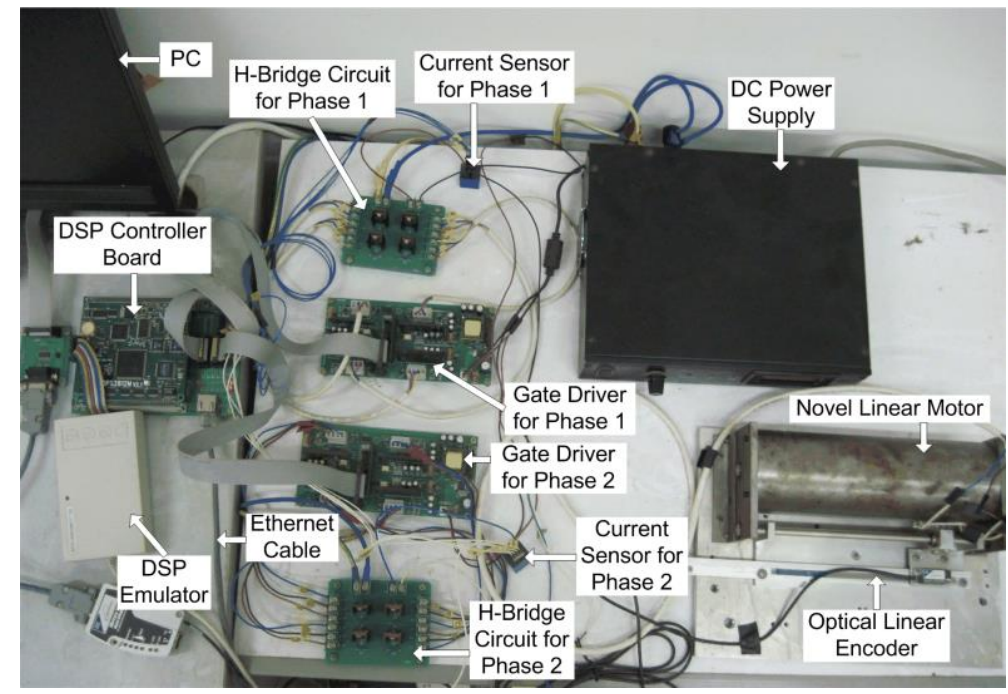

\section{Figure 6. Experimental Setup of Linear Motor Positioning Control System}

\subsection{Experimental Results and Discussion}

Position Step Response Performance Of The Linear Motor Positioning Control System Is Tested By Both Simulation And Actual Experiment. Here, The Desired Position Is Set As $45 \mathrm{Mm}$. At The Very Beginning, The Calculated Control Input Is Given To Phase 1 Only. The Current Switches From Phase 1 To Phase 2 At $25 \mathrm{Mm}$ By Giving The Calculated Control Input To Phase 2 Directly And Phase 1 Is Powered Off. Current Signal Of Each Phase Is Sampled At A Period Of 0.04 Ms And The Sampling Period Of Position Signal Is Determined As 1 Ms. The Entire System Is Simulated With Matlab/Simulink Program Package And Parameters Of Each ADRC Are Established In Table 3. Simulation And Experimental Results Of The Position Step Response Are Shown Together In Figure 7.

It Can Be Seen From Figure 7 That The Smooth And Precise Positioning Linear Motion Has Been Achieved. The Position Step Response Is Smooth Without Any Overshoot Or Oscillation, And The Final Position Error Is Less Than $10 \mathrm{Mm}$. The Resolution Of Position Sensor Is $5 \mathrm{Mm}$. Figure 8 Shows Current Waveforms Of Phase 1 And Phase 2 In The Commutation Process. From Figure 7 And Figure 8, It 
Can Be Seen That The Current Commutation Process Doesn't Have Significant Influence On The Smooth Linear Motion.

In Addition, Controller Parameters Used In The Simulation And The Experiment Are The Same. Meanwhile, There Are Some Differences Between The Mathematical Model Used For Simulation And The Actual System, Such As Inaccurate Plant Parameters And Uncertain Disturbances. Nevertheless, Experimental Results Agree With Simulation Results Very Well Except Some Delay, Which Is Caused By The Uncertain Friction. All Of These Illustrate That The ADRC Is Robust Against Uncertainties.

Table 3. Parameters of Adrcs

\begin{tabular}{cccc}
\hline $\begin{array}{c}\text { Parameter } \\
\mathrm{s}\end{array}$ & $\begin{array}{l}\text { ADR } \\
\text { C1 }\end{array}$ & $\begin{array}{l}\text { ADR } \\
\text { C2 }\end{array}$ & $\begin{array}{l}\text { ADR } \\
\text { C3 }\end{array}$ \\
\hline$H$ & 0.001 & 0.001 & 0.000 \\
& & & 04 \\
$B$ & 30 & 550 & 200 \\
$B_{1}$ & 0 & 1000 & 2500 \\
$B_{2}$ & 0 & 1976 & 2470 \\
$A$ & 0.5 & 0.5 & 530 \\
$\Delta$ & 0.1 & 0.1 & 0.000 \\
& & 7200 & 04 \\
$B$ & 0 & 0 & 226 \\
\hline
\end{tabular}

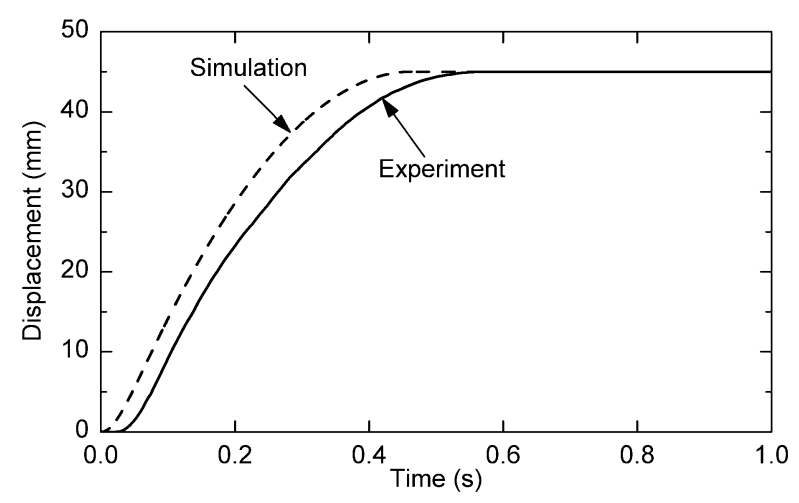

Figure 7. Simulation and Experimental Results of Position Step Response 


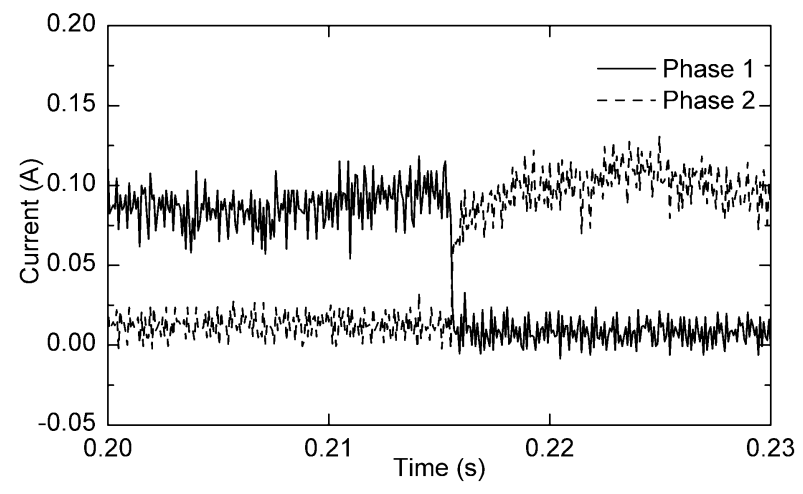

Figure 8. Phase Current Waveforms in Commutation Process

\section{Conclusions}

A Novel Linear Motor Has Been Proposed In This Paper, Which Possesses The Advantages Of Simple Operation And Ripple Force Reduction. The Positioning Control System Based On Cascaded ADRC Has Been Realized Experimentally. Simulation And Experimental Results Show That Less Than $10 \mathrm{Mm}$ Positioning Error Has Been Achieved Without Any Overshoot Or Oscillation. The System Provides A Suitable Solution For Smooth And Precise Positioning Linear Motion Applications Such As Robotics, Multi-Degree-Of-Freedom Motion Platform, And Medical Instruments. For Further Study, Effects Of Phase Commutation On Motion Smoothness At High Speed Will Be Investigated.

\section{Acknowledgement}

This Work Was Supported By The Natural Science Foundation Of Jiangsu Province, China [Grant Number BK20130744]; The Scientific Research Foundation Of Nanjing Institute Of Technology [Grant Number YKJ201220]; And The National Natural Science Foundation Of China [Grant Number 61104085]. The Authors Would Like To Express Their Appreciation To The Sponsors.

\section{References}

[1] J.-H. Choi, S. Kim, D. S. Yoo and K.-H. Kim, "A DSP-Based Robust Position Controller Of A SingleSided Linear Induction Motor For Automatic Picking System", International Journal Of Control And Automation, Vol. 7, No. 6, (2014), Pp. 325-338.

[2] H. Itagaki And M. Tsutsumi, "Control System Design Of A Linear Motor Feed Drive System Using Virtual Friction", Precision Engineering, Vol. 38, No. 2, (2014), Pp. 237-248.

[3] O. Gomis-Bellmunt, S. Galceran-Arellano, A. Sudria-Andreu, D. Montesinos-Miracle And L. F. Campanile, "Linear Electromagnetic Actuator Modeling For Optimization Of Mechatronic And Adaptronic Systems", Mechatronics, Vol. 17, No. 2, (2007), Pp. 153-163.

[4] H. M. Khalil and M. El Bardini, "Support Vector Machines Based Adaptive Controller For Piston Hydraulic Motor", International Journal Of Control And Automation, Vol. 4, No. 3, (2011), Pp. 31-50.

[5] J. Ji, S. Yan, W. Zhao, G. Liu And X. Zhu, "Minimization Of Cogging Force In A Novel Linear Permanent-Magnet Motor For Artificial Hearts", IEEE Transactions On Magnetics, Vol. 49, No. 7, (2013), Pp. 3901-3904.

[6] A. Shiri And A. Shoulaie, "Design Optimization And Analysis Of Single-Sided Linear Induction Motor, Considering All Phenomena", IEEE Transactions On Energy Conversion, Vol. 27, No. 2, (2012), Pp. 516-525.

[7] Y. Fujimoto, T. Kominami and H. Hamada, "Development And Analysis Of A High Thrust Force Direct-Drive Linear Actuator", IEEE Transactions On Industrial Electronics, Vol. 56, No. 5, (2009), Pp. 1383-1392. 
[8] C. Hu, B. Yao And Q. Wang, "Performance-Oriented Adaptive Robust Control Of A Class Of Nonlinear Systems Preceded By Unknown Dead Zone With Comparative Experimental Results", IEEE/ASME Transactions On Mechatronics, Vol. 18, No. 1, (2013), Pp. 178-189.

[9] W.-J. Kim and B. C. Murphy, "Development Of A Novel Direct-Drive Tubular Linear Brushless Permanent-Magnet Motor", International Journal Of Control, Automation And Systems, Vol. 2, No. (2004), Pp. 279-288.

[10] O. Ustun and R. N. Tuncay, "Design, Analysis, And Control Of A Novel Linear Actuator", IEEE Transactions On Industry Applications, Vol. 42, No. 4, (2006), Pp. 1007-1013.

[11] M. G. Lee, S. Q. Lee and D.-G. Gweon, "Analysis Of Halbach Magnet Array And Its Application To Linear Motor", Mechatronics, Vol. 14, No. 1, (2004), Pp. 115-128.

[12] S. Sheel And O. Gupta, "High Performance Fuzzy Adaptive Pid Speed Control Of A Converter Driven DC Motor", International Journal Of Control And Automation, Vol. 5, No. 1, (2012), Pp. 71-88.

[13] C. Xia, Z. Li And T. Shi, "A Control Strategy For Four-Switch Three-Phase Brushless Dc Motor Using Single Current Sensor", IEEE Transactions On Industrial Electronics, Vol. 56, No. 6, (2009), Pp. 20582066.

[14] L. Lu, Z. Chen, B. Yao And Q. Wang, "A Two-Loop Performance-Oriented Tip-Tracking Control Of A Linear-Motor-Driven Flexible Beam System With Experiments", IEEE Transactions On Industrial Electronics, Vol. 60, No. 3, (2013), Pp. 1011-1022.

[15] S. Pal and N. S. Tripathy, "Remote Position Control System Of Stepper Motor Using DTMF Technology", International Journal Of Control And Automation, Vol. 4, No. 2, (2011), Pp. 35-42.

[16] M.-Y. Chen and J.-S. Lu, "High-Precision Motion Control For A Linear Permanent Magnet Iron Core Synchronous Motor Drive In Position Platform", IEEE Transactions On Industrial Informatics, Vol. 10, No. 1, (2014), Pp. 99-108.

[17] X. Shi, H. Li And J. Huang, "A Practical Scheme For Induction Motor Modelling And Speed Control", International Journal Of Control And Automation, Vol. 7, No. 4, (2014), Pp. 113-124.

[18] C.-S. Ting and Y.-N. Chang, "Observer-Based Backstepping Control Of Linear Stepping Motor", Control Engineering Practice, Vol. 21, No. 7, (2013), Pp. 930-939.

[19] M. Jang, J.-Y. Choi, S.-H. Lee, H.-W. Cho and W.-B. Jang, "Analysis And Experimental Verification Of Moving-Magnet Linear Actuator With Cylindrical Halbach Array", IEEE Transactions On Magnetics, Vol. 40, No. 4, (2004), Pp. 2068-2070.

[20] Z. Xu and S. Chang, "Improved Moving Coil Electric Machine For Internal Combustion Linear Generator", IEEE Transactions On Energy Conversion, Vol. 25, No. 2, (2010), Pp. 281-286.

[21] X. Shi and S. Chang, "Commutation Force Ripple Reduction In A Novel Linear Brushless Dc Actuator Based On Predictive Current Control", Electric Power Components And Systems, Vol. 39, No. 15, (2011), Pp. 1609-1620.

[22] H.-L. Xing, J.-H. Jeon, K. C. Park and I.-K. Oh, "Active Disturbance Rejection Control For Precise Position Tracking Of Ionic Polymer-Metal Composite Actuators", IEEE/ASME Transaction On Mechatronics, Vol. 18, No. 1, (2013), Pp. 86-95.

[23] J. Han, "From PID To Active Disturbance Rejection Control", IEEE Transactions On Industrial Electronics, Vol. 56, No. 3, (2009), Pp. 900-906.

\section{Authors}

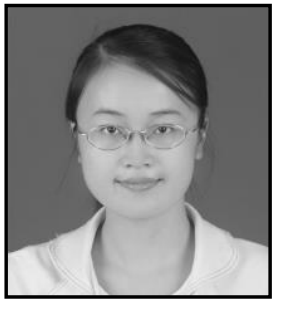

Xinxin Shi received The B.Eng. And Ph.D. Degrees In Mechatronic Control Engineering From Nanjing University Of Science And Technology, Nanjing, China, In 2007 And 2012, Respectively. She Is Currently A Lecturer In The School Of Automation, Nanjing Institute Of Technology, Nanjing, China. Her Research Interests Include Motion Control Of Induction Motors, Precision Motion Control Of Electromagnetic Linear Motor, Active Disturbance Rejection Control, And Robotics.

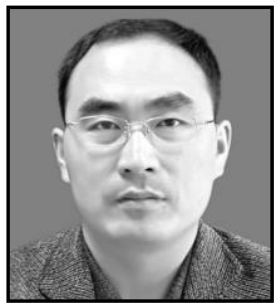

Jiacai Hua received The B.Eng., M.Eng., And Ph.D. Degrees In Control Theory And Engineering From Jilin University, Changchun, China, In 2000, 2003, And 2006, Respectively. He Is Currently A Professor In The School Of Automation, Nanjing Institute Of Technology, Nanjing, China. His Research Interests 
International Journal of Control and Automation

Vol.8, No.8 (2015)

Include Motion Control Of Motors, Intelligent Control, And Signal Processing. 